\title{
Recommended Storage Atmospheric Pressure
}

National Cancer Institute

\section{Source}

National Cancer Institute. Recommended Storage Atmospheric Pressure. NCI

Thesaurus. Code C101705.

The recommended storage atmospheric pressure for a device. 